Female athletes and sexual harassment

Performance level and sexual harassment prevalence among female athletes in the

\title{
Czech Republic
}

By

Kari Fasting ${ }^{1}$, Celia Brackenridge ${ }^{2}$ and Nada Knorre ${ }^{3}$

1. Norwegian School of Sport Sciences, Oslo, Norway

2. Centre for Youth Sport and Athlete Welfare, Brunel University, UK

3. Czech Olympic Committee

\section{Contact for correspondence:}

Professor Kari Fasting,

Norwegian School of Sport Sciences,

Box 4014, Ullevål Stadion

0806 Oslo

Norway

Tel: +4723262405

Fax: +47 23262414

kari.fasting@nih.no 
Female athletes and sexual harassment

\begin{abstract}
The results presented in this article are from a larger research project on issues related to women in sport in the Czech Republic. The article tries to answer research questions related to whether there are any relationships between the experience of sexual harassment among female athletes inside and outside sport, and at different sport performance levels. The sample, totalling 595 women, was divided into three performance groups: elite, competing and exercisers. No significant differences were found between the different performance groups in relation to their experience of sexual harassment. When we their experiences inside and outside sport were examined this picture changed: the chance of being harassed from someone in sport increased with performance level, from $29.7 \%$ among the exercisers to $55.2 \%$ among the elite level athletes. The group with the highest proportion experiencing sexual harassment, however, was the exercises outside of sport, at $73 \%$. The high prevalence of sexual harassment is discussed in relation to the gender order in the Czech society. The difference between the performance groups' experiences inside and outside sport offer some confirmation to the proposition that being a competitive athlete, which is associated with physical strength and high self esteem, may offer a degree of protection from harassment outside sport.
\end{abstract}

Keywords: elite sport, women, sexual violation 
Female athletes and sexual harassment

\section{Introduction}

The results presented in this article are from a larger research project on issues related to women in sport in the Czech Republic. The project was initiated by the Women and Sport Committee of the Czech Olympic Committee in cooperation with the Czech Sport Union. The goal of the research was to assess the present role and situation of women in sport organisations in the Czech Republic. One of the main research questions addressed female athletes' experiences of sexual harassment.

Previous research on sexual harassment among athletes has generally been guided by assumptions about the pattern of gender relations in sport more widely (Fasting \& Brackenridge, 2007). Sport has often been conceptualized as a male-dominated culture which facilitates various forms of discrimination against female athletes, including sexual harassment from coaches and male athletes (Messner \& Sabo, 1994; Volkwein et al., 1997; Messner, 2002). Indeed, a Norwegian study indicated that female elite athletes suffer higher levels of sexual harassment while inside sport (from authority figures) than their non-sport peers experience outside sport (from teachers/supervisors) (Fasting et al., 2003).

Conversely, researchers have argued that athletic participation can protect female athletes from sexual victimization through a variety of social-psychological mechanisms (Miller et al.,1999; Choi, 2000; Haywood \& Dworkin, 2003). These accounts suggest that sport is a source of empowerment in many girls' lives, helping them to develop a positive body image and identity and to make confident choices about relationships and sexuality. To this extent, and within the context of research and theory on sexual harassment prevention, sport might be said to protect females from some forms of sexual 
Female athletes and sexual harassment

victimisation. Fasting et al. (2003) also suggested that sport offers some protection to female athletes because it develops their strength, self-confidence and sense of physical adeptness, characteristics which have previously been associated with resistance and rape avoidance (Bart, 1981). Limited support for this hypothesis was found in a large dataset from college-aged students in the USA (Fasting et al., 2008).

In relation to sport performance level, most of the research on the prevalence of sexual harassment in sport has been conducted on elite or former elite level female athletes (Brackenridge, 2001). The study of Norwegian elite level females athletes by Fasting et al. (2000) found a higher prevalence of sexual harassment among the very best athletes (those who had participated in a World Championship and/or the Olympic Games) compared with elite level female athletes in the sample who not had participated in international championships.

Based on her qualitative research in the Netherlands, Cense (1997) suggested that the risk factors for sexual harassment in top level sport are different from those in recreational sport. In recreational sport the power relationship was less influential than the 'organisation sexuality' (Hearn et al., 1989) and the gender culture in the clubs. This culture was often characterised by sexual permissiveness, with many remarks and jokes from men about the appearance and sex lives of women.

In their study of sexual harassment and abuse in Australian sport, Leahy et al. (2002) compared prevalence data between elite and club-level athletes: the elite group reported significantly higher rates of sexual abuse in sport than did the club group but, as with other studies of sexual harassment in sport (Kirby et al., 2000; Volkwein et al., 1997), data were not collected from exercisers. Accordingly, relatively little is known 
Female athletes and sexual harassment

about the comparative sexual harassment experiences of non-elite athletes and exercisers. Further, we know of no published data from sport on this topic in former communist countries.

From the literature, we identified the following research questions:

1. Does the prevalence of sexual harassment of female athletes overall differ when they are inside and outside sport?

2. Does the prevalence of sexual harassment differ between female elite athletes, non-elite athletes and exercisers?

3. Are there any differences in the prevalence of sexual harassment among elite athletes, non-elite athletes and exercisers when inside and outside sport?

\section{Material and methods}

\section{Sample characteristics}

A total of 595 women participated in the study, comprising 169 elite level athletes, 212 from the club level and 214 sport students. The sport students were recruited from the three Universities in Czech Republic where it is possible to study sport: Charles University in Prague, Palackeho University in Olomouc, and Masaryk University in Brno. Most of the students were in their third or fourth year. The club level athletes and the elite level athletes lived all over the country. Most of the elite level athletes lived in Prague.

The participants were divided into three performance level groups for the purpose of analysing the sexual harassment data: elite level athletes $(n=229)$, non-elite level athletes $(n=224)$ and exercisers $(n=142)$. The criteria for inclusion in the elite group were 
Female athletes and sexual harassment

that the athletes should train at least four times a week and have participated in an Olympic Games, a European Championship or a World Championship, or competed at international level within the previous 1-2 years. The non-elite level group consisted of those athletes who were competing in sport but who did not qualify for the elite group. The exercisers were those simply practising sport but who did not compete.

The average age of the participants was 22.8 years with the youngest being 15 years old and the oldest 55 years old. The elite athletes were the youngest (mean=21.8 years) and the exercisers oldest (mean $=23.7$ years).

Almost half of the respondents lived with their parents. Nineteen percent lived with a partner and $6 \%$ cent with a partner and a child: only $1 \%$ lived alone with one child or more. More elite level athletes than athletes in the two other groups lived alone (13\%) and more exercisers than in the two other groups had children and lived with a partner or husband (13\%). Forty three of the participants had one or more children: 29 had two children, 14 had one child. Among the exercisers 17 had children, among the non-elite group this number was 14, and among the elite athletes it was 12. About two thirds of the participants in the study were students, and about half of these again were sport students. As an indicator of social class we surveyed the educational background of the participants' parents. Those for whom either one or both parents had a college/university degree were characterised as high educational background (56\%) and the rest as low (44\%). There were no significant differences in parents' educational background between the three performance groups.

\section{Methods}


Female athletes and sexual harassment

Data were gathered through a questionnaire, which was written in English, then translated back and forth between Czech and English to ensure that the Czech version had the correct meaning. It was also pilot tested on a group of 10 people representing different kinds of involvement in sport.

Data collection took place where the athletes were training and where the students were studying. The reasons for not doing the survey through the mail were twofold: first, we wanted to secure the highest possible response rate and secondly, we wanted the participants to have the opportunity to ask questions if there was something in the questionnaire that they did not understand, wondered about or were insecure about how to answer. The questionnaires were coded and analyzed with SPPS version 13 (Statistical Program Package for Social Sciences). Chi square tests were used to test the relationship between variables in the cross-tables. Testing for difference in experience of sexual harassment inside sport in proportion to experience of sexual harassment outside sport was carried out by the use of a nonparametric binomial test. This is an exact test of the statistical significance of deviation from one distribution of observations in a category (experience of sexual harassment inside sport), compared with the distribution of observations in another (experience of sexual harassment outside sport).

Within the overall questionnaire on sport experiences, three questions measuring the athletes' experiences of sexual harassment were asked. It is important to note that for sexual attention to be defined as sexual harassment it must have been experienced as unwanted or threatening, troublesome, insulting or offensive. One issue frequently discussed in the research literature on sexual harassment is that women will report experiencing unwanted sexually harassing behaviours but not necessarily label those 
Female athletes and sexual harassment

experiences as sexual harassment (Barak et al., 1992; Welsh et al., 2006). For example, in a comparative study among American and Brazilian female students there was a large discrepancy between the prevalence of sexual harassment when objectively and subjectively defined and measured (Barak, 1997). Accordingly, we deemed it particularly important to measure the participants' objectively experienced behaviors, particularly because sexual harassment was virtually a non-issue in the Czech Republic, both in sport and in society at large, when data gathering was underway. Therefore, we asked the athletes if they had ever experienced the following situations:

a) Unwanted physical contact, body contact (for example pinching, hugging, fondling, being kissed against your will, etc).

b) Repeated unwanted sexually suggestive glances, comments, teasing and jokes, about your body, your clothes, your private life, etc.

c) Ridiculing of your sport performance and of you as an athlete because of your gender or your sexuality (for example 'Soccer is not suitable for girls').

For each of these questions, participants were asked to mark whether they had experienced it from a male or female coach, a male or female peer-athlete, a male or female member of the sport management team, a male or female teacher, a male or female peer-student, a male or female family member, and/or from other males or females outside the sport or family. In presenting the results, experience of sexual harassment means that a respondent marked one or more forms of sexual harassment: it does not indicate the severity, frequency or total number of these experiences. Experience of sexual harassment from someone inside sport means that a respondent marked one or 
Female athletes and sexual harassment

more of the categories 'from a coach', 'members of the sport management team', 'and/or peer athletes'. Experience of sexual harassment from someone outside sport means that one or more of the following categories were marked: 'teacher', 'peer-student', 'family member' and/or 'males or females outside the sport family'.

\section{Trustworthiness}

We could find no trace of formal ethics procedures for social sciences in the Czech Republic when this study was undertaken. Therefore, we followed careful guidelines that conform to good research practice elsewhere (APA, 2003). Before the completing the questionnaire, participants were informed that the results would be presented in such a way that it would be impossible to recognise any individual, or even any specific sport. Since some very high profile female athletes participated in the study, in order to secure valid answers from them it was important that they trusted us completely in relation to confidentiality. This was also important for all participants since some quite personal and sensitive questions were asked.

Other factors that might have influenced the validity of the data were coding and data entry. Two research assistants systematically checked each other's coding to reduce errors. In addition, further visual scrutiny of the data was conducted to identify data entry mistakes. There is therefore no reason to believe that our data do not have a high degree of validity. The participants in the study represented 68 different sports and physical activities in total. In addition, we are confident that there was a good geographical representation across the country and that the results can thus be generalized to other Czech female athletes beyond our sample. 
Female athletes and sexual harassment

\section{Results}

Altogether, $72 \%$ of the athletes who responded to this survey had experienced some form of sexual harassment. As found in other studies (Fasting et al., 2003), the Czech athletes had experienced sexual harassment more often from someone outside sport $(58.3 \%)$ than someone inside sport (44.9\%). Regarding research question 1, 'Does the prevalence of sexual harassment of female athletes overall differ when they are inside and outside sport?' the answer for these Czech athletes is therefore 'yes'.

[Insert Fig 1 about here]

Figure 1 shows that there are no significant differences between the three performance level groups in relation to sexual harassment experienced. The answer to research question 2, 'Does the prevalence of sexual harassment differ between female elite athletes, non-elite competing athletes and exercisers?' is therefore 'no'.

\section{[Insert Table 1 about here]}

Finally, regarding research question 3, 'Are there any differences in the prevalence of sexual harassment among elite athletes, non-elite athletes and exercisers when inside and outside sport?', Table 1 shows that the chances of being harassed from someone in sport increase with performance level, from $29.7 \%$ among the exercisers to $55.2 \%$ among the elite level athletes. But there is a much higher chance of being sexually harassed by someone outside sport for a woman belonging to the exercise group $(73.2 \%)$ compared with one who is a sport competitor $(53.2 \%)$ or elite athlete (54.1\%). Among the elite level athletes there is no difference in the prevalence rate of experienced sexual harassment when inside or outside sport. The difference that was found in answering research question one is therefore only valid for the two other performance groups, whose 
Female athletes and sexual harassment

participants experienced more sexual harassment outside than inside a sporting environment.

\section{Discussion}

The prevalence of sexual harassment among this group of Czech athletes is very high, both inside and outside sport, when compared with data from similar studies in sport from other countries reported above But it is almost impossible to compare harassment prevalence rates internationally due to: differences in sampling procedures, methodological approaches, vocabulary and connotative meaning of questionnaire items, anonymity and confidentiality of disclosures etc. (Barak, 1997).

The comparatively high prevalence of sexual harassment among this participant sample should be seen in the context of the overall gender order in the Czech society (Vaskakova, 2006). Equal rights between women and men in a society, as well as whether sexual harassment is prohibited by law, may be crucial in relation to the prevalence of sexual harassment. Equal rights and harassment legislation did not exist in the Czech Republic when the data for this project were being collected. On the other hand, studies from other countries which have had such legislation in place for some years indicate that the problems appear to be more complicated (Timmermann and Bagemer, 1999). Vaskova (2006) points out that both past and current sociological research reveals that a certain tolerance for mild forms of sexual harassment is characteristic of Czech society. This is also supported by Vesinova-Kalivodova (2005) who argues that the Czech Republic is both a pre-feminist and post-communist society and focussed on substantial differences between new and old democracies in relation to 
Female athletes and sexual harassment

the European Union and its policy on gender equality. Marcela Linkova (2004) agrees, arguing that this is linked to a chauvinist culture associated with the communist past of the country (Haerpfer, 2002; Girginov, 2004).

Many authors have stated that sexual harassment is primarily about control and power but especially the kind of power which is based on the gender order, i.e. the privileges of heterosexual masculinity. From a feminist perspective, men's power over women has been related not only to individual men with power over women but also, according to Connell (2002), to patriarchal power which has been institutionalised and officially supported. From a social structural gender perspective, one could argue that the experiences reported in this study may be explained by the use of sexual harassment as a mechanism for suppressing women and attempting to keep or reinforce men's dominance over them.

The higher percentage of sexual harassment experienced by the athletes overall outside sport compared with inside sport is primarily due to the experiences of the nonelite respondents. In relation to the possible protection from sexual harassment afforded to athletes, mentioned in the introduction, the data here offer some confirmation of this concept i.e. that being a competitive female athlete may offer some protection from being harassed outside sport compared with being merely an exerciser. Being outside a sporting environment, being physically strong and having high self esteem - all outcomes associated with female sport - may thereby protect women from harassing situations in general. However, inside sport this proposition does not seem to fit, since the highest risk group within sport is the elite athletes. This finding may indicate something about the particular culture of elite level sport. The elite sport milieu is dominated by a hetero- 
Female athletes and sexual harassment

patriarchal culture (Pronger, 1990) and an unequal power balance between men and women, just as is shown by the image of the Czech Republic reflected in this study. In addition to the emerging research trend showing increased risk at the highest performance levels, identified above, there is also some evidence from practice that coaches at this level are more resistant than their peers at lower performance levels to educational interventions that attempt to transform coach-athlete power relations and culture in elite sport (Collins, in press).

\section{Perspective statement}

This study helps to illuminate previously unreported data about the sexual harassment of female athletes in an under-researched cultural location - the Czech Republic. To avoid perpetuating the bias of white, middle class, social democratic cultures in sport science and medicine, it is vital that systematic research is conducted in all ideological and political locations. Then IOC Medical Commission has produced a Consensus Statement on Sexual Harassment and Abuse in sport (IOC, 2007) which urges practical steps to improve athlete safety and health. At the same time, UNICEF is working towards the implementation of a global violence prevention strategy and now includes sport within this remit (Brackenridge et al., in press). Only through international cooperation, and with a strong evidence base, will such initiatives impact successfully on athlete safety and health.

\section{Acknowledgement}

This article is an expanded version of a paper presented at the ISSA Conference in Copenhagen $31^{\text {st }}$ July $-5^{\text {th }}$ August 2007. 
Female athletes and sexual harassment

\section{References}

American Psychological Association (2003). Ethical Principles of Psychologists and Code of Conduct. http://www.apa.org/ethics/code2002.html Retrieved 2 Sept 2008.

Barak, A. (1997). 'Cross-cultural perspectives on sexual harassment', in: W. O'Donahue (Ed.), Sexual harassment: Theory, research, and treatment (pp. 263-300). Boston, MA: Allyn \& Bacon.

Barak, A., Fisher, W.A. and Houston, S. (1992). Individual difference correlates of the experience of sexual harassment among female university students. Journal of Applied Social Psychology 22, 17-37.

Bart, P.B. (1981). A study of women who were both raped and avoided rape. Journal of Social Issues, 37, 4.

Brackenridge, C.H., Fasting, K., Kirby, L. and Leahy, T. (in press) Exercising Rights: Eliminating violence against children in sport. UNICEF Innocenti Research Centre, Florence, Italy: UNICEF.

Cense, M. (1997). Rode Kaart of Carte Blanche: Risicofactoren voor seksuelle intimidatie en seksueel misbruik in de sport, Arnhem: Netherlands Olympic Committee*Netherlands Sports Federation/TransAct.

Cense, M. and Brackenridge, C.H. (2001). Temporal and developmental risk factors for sexual harassment and abuse in sport, European Physical Education Review, 7(1): 61-79. Choi, P.Y.L. (2000) Femininity and the Physically Active Woman. London: Routledge. Collins, T. (in press). 'Child protection in high performance British gymnastics', in: C.H. Brackenridge (ed) Sport, Children's Rights and Violence Prevention: A Sourcebook on 
Female athletes and sexual harassment

Global Issues and Local Programmes. UNICEF Innocenti Research Centre, Florence, Italy: UNICEF.

Connell, R.W. (2002). Gender. Sydney: Polity Press

Fasting, K., Brackenridge, C.H., Miller, K.E. and Sabo, D. (2008) 'Participation in college sports and protection from sexual victimization', International Journal of Sport and Exercise Psychology, Special Issue: Abuse and Harassment in Sport Implications for the Sport Psychology Profession (Edited by T. Leahy), 16(4): pp. tbc

Fasting, K. and Brackenridge, C.H. (2007). Women athletes' personal responses to sexual harassment in sport. Journal of Applied Sport Psychology 19, 419-433.

Fasting, Brackenridge and Sungot-Borgen (2003). Experiences of sexual harassment and abuse amongst Norwegian elite female athletes and non-athletes, Research Quarterly for Exercise and Sport 74, 1, 84-97.

Girginov, V. (2004). Totalitarian sport: Towards an understanding of its logic, practice and legacy. Totalitarian Movements and Political Religions, 5, 1, 25-58.

Haerpfer, C. W. (2002) Democracy and Enlargement in Post-Communist Europe The Democratisation of the General Public in 15 Central and Eastern European Countries, 1991-1998. London: Routledge.

Haywood, L. and Dworkin, S.L. (2003) Built to Win: The female athlete as cultural icon. London: University of Minnesota Press.

Hearn, J., Sheppard, D., Tancred-Sheriff, P. and Burrell, G. (eds.) (1989). The Sexuality of Organisation. London: Sage.

International Olympic Committee. (2007). Consensus Statement on Sexual Harassment and Abuse in Sport. Lausanne: IOC. 
Female athletes and sexual harassment

http://www.olympic.org/uk/organisation/commissions/medical/full_story_uk.asp?id=153

$\underline{9}$, retrieved $27^{\text {th }}$ November 2007.

Kirby, S. and Greaves, L. (1996). 'Foul play: Sexual abuse and harassment in sport', paper presented to the Pre-Olympic Scientific Congress, Dallas, USA, July 11-14.

Leahy, T., Pretty, G. and Tenenbaum, G. (2002). Prevalence of sexual abuse in organized competitive sport in Australia. Journal of Sexual Aggression 8, 2, 16-36.

Messner, M.A. \& Sabo, D. (eds.) (1994). Sport, Men and the Gender Order. Champaign, IL: Human Kinetics.

Miller, K. E., Sabo, D., Melnick, M., Farrell, M. P. and Barnes, G. (2000). Health Risks and the Teen Athlete. A Women's Sports Foundation research project. Eisenhower Park, NY: Women's Sports Foundation.

Pronger, B. (1990) The Arena of Masculinity: Sports, homosexuality, and the meaning of sex. London: GMP Publishers Ltd.

Sabo, D., Miller, K. E., Melnick, M., Farrell, M. P. and Barnes, G. M. (1998). The

Women's Sports Foundation Report: Sport and Teen Pregnancy. Eisenhower Park, NY:

Women's Sports Foundation.

Timmermann and Bagemer, (1999) XXXX

Vaskakova, XX (2006) XXXX

Volkwein, K., Schnell, F., Sherwood, D. and Livezey, A. (1997). Sexual harassment in sport: Perceptions and experiences of American female student-athletes. International Review for the Sociology of Sport 23, 3, 283-295.

Welsh, XX et al. (2006) XXXX 
Female athletes and sexual harassment

Table 1. Female athletes' experiences of sexual harassment seen in relation to performance level

\begin{tabular}{|l|cc|cc|}
\hline Performance & \multicolumn{2}{|c|}{ Inside sport } & \multicolumn{2}{|c|}{ Outside sport } \\
Group Level & n & \% & n & \% \\
\hline Elite & 123 & 55 & 120 & 54 \\
\hline Competing & 94 & 44 & 115 & 53 \\
\hline Exercising & 41 & 30 & 101 & 73 \\
\hline Total & & & & 58 \\
\hline
\end{tabular}

